\title{
Thrombocythemia with distal limb defects
}

INSERM

\section{Source}

INSERM. (1999). Orphanet: an online rare disease and orphan drug data base.

Thrombocythemia with distal limb defects. ORPHA:329319

Thrombocythemia with distal limb defects is a rare, genetic syndrome with limb reduction defects characterized by thrombocytosis, unilateral transverse limb defects (ranging from absence of phalanges to absence of hand or forearm) and splenomegaly. 